\title{
The evolutionary causes of egg rejection in European thrushes (Turdus spp.): a reply to M. Soler
}

\author{
Peter Samas ${ }^{1}$, Mark E Hauber ${ }^{2}$, Phillip Cassey ${ }^{3}$ and Tomas Grim ${ }^{1 *}$
}

\section{Correspondence}

A response to: Soler: No evidence of conspecific brood parasitism provoking egg rejection in thrushes. Frontiers in Zoology 2014, 11:68.

Several species of European thrushes (genus Turdus) reject foreign eggs, yet the evolutionary causes of this behavior remained unclear. Recently, we concluded that conspecific (CBP), rather than interspecific brood parasitism (IBP) is responsible for the patterns of foreign egg rejection in these taxa [1]. In his comment M. Soler does not agree with this conclusion. Here we address each of his four main points to demonstrate the principles that (i) a theory is never out of date but is either supported or discredited, and (ii) it is not the use of references, but instead the collection and analysis of new data, which advances scientific progress.

First, Soler argues that the costs of $\mathrm{CPB}$ are too low to select for the evolution of host defenses and that the foreign eggs are too similar to host eggs for effective discrimination. That costs of CPB seem to be generally low across various species does not necessarily mean that such costs are always low (see also p. 51 in [2]). For example, IBP is generally highly costly to hosts but in several hosts of the brown-headed cowbird (Molothrus ater), there is little or no detectable cost of IBP [3]. Regarding egg similarity, inter-clutch variation in both Turdus species that we studied is sufficiently high to allow for foreign conspecific egg discrimination both in theory [4] and in reality [1].

Second, Soler takes issue with the maintenance versus decay of egg rejection behaviors as an antiparasitic host defense in the absence of ongoing brood parasitism. Crucially, the empirical studies referenced by Soler reported that the rejection costs associated with the ejection

\footnotetext{
* Correspondence: tomas.grim@upol.cz

'Department of Zoology and Laboratory of Ornithology, Palacký University,

17 listopadu 50, CZ-771 46 Olomouc, Czech Republic

Full list of author information is available at the end of the article
}

of foreign eggs were essentially nil. In contrast, we documented non-negligible rejection errors and costs, even in response to foreign conspecific eggs. Therefore our study system does not fit the critical assumption of Soler's argument which holds only for "a trait which does not decrease individual fitness".

Third, Soler argues that aggression towards cuckoo dummies combined with the foster parents' reluctance to feed cuckoo nestlings are a clear indication of past evolutionary exposure to IBP. This argument is flawed (see [5]). Song thrush (Turdus philomelos) show very low and nonspecific aggression towards cuckoo dummies and cuckoo chicks in experimental nests die not because of host chick discrimination but because the smooth nest-cup design prevents successful eviction of host nestmates by the hatchling cuckoo, forcing it into fatal competition with host chicks. In turn, blackbirds (T. merula) are aggressive not only to cuckoo dummies but to any intruders near their nests, including harmless pigeons (Columba livia), indicating that their aggression did not specifically evolve in response to IBP [6]. Cuckoo chicks cross-fostered to blackbird nests also do not survive to fledging but not because blackbirds were reluctant to feed cuckoo chicks, as the parasitic nestling's mass typically increased with time [7]; instead, cuckoo chicks "had bloated bellies and suffered from diarrhea" implying that it is the types of food delivered by blackbirds that caused cuckoo deaths (p. 719 in [7]). In general, switching to new types of food is an unlikely defence against brood parasite chicks: it would be maladaptive for any hosts to evolve novel food habits as a defense against IBP because such change would not prevent most costs of IBP (see [8]).

Last, Soler pointed out that reported current rates of CBP in thrushes are too low to select for CBP discrimination, and should be much higher (e.g., estimated to be at least 22\% in black-billed magpie Pica hudsonia: [9]). However, although their calculations included non- 
negligible discrimination errors and costs in that host species, its clutch size is $50-100 \%$ higher than those of thrushes (especially in New Zealand: [10]), rendering the cost of parasitism in magpies relatively low, and thus predicting the cost threshold for the evolution of CBP rejection relatively high compared to our taxa. Furthermore, as we explained [1], we severely underestimated parasitism rates in our study populations. Moreover, high current parasitism rates are not critical to provide support for CBP hypothesis; previously [11] supported CBP scenario based on current CBP rates of $2.7 \%$ in their study population of house sparrows (Passer domesticus).

Studies of IBP hosts routinely interpret high rejection of foreign eggs in the absence of current IBP as an evidence of historical IBP. We do not see any empirical or theoretical arguments that would prevent us from applying the identical logic to CBP systems. Just like in any other area of evolutionary biology, so in the study of IBP and $\mathrm{CBP}$ we should be able to infer past evolutionary causes events from present biological evidence. However, we agree with M. Soler that any conclusions based on such indirect evidence are essentially probabilistic. Accordingly, we can never reliably reconcile how important role CBP or IBP played in long past in virtually any species - including current suitable hosts of IBP which might have evolved their egg discrimination due to past CBP and not IBP [1]. However, the large-scale geographic and comparative approaches used by [5] and [1] demonstrate one way to overcome at least some of the limitations of inferring evolutionary forces responsible for the existence of current adaptations in organisms.

\section{Acknowledgments}

Our work is supported by the Human Frontier Science Program RGY69/2007 (to TG, PC \& MEH) and RGY83/2012 (to MEH \& TG).

\footnotetext{
Author details

'Department of Zoology and Laboratory of Ornithology, Palacký University, 17 listopadu 50, CZ-771 46 Olomouc, Czech Republic. ${ }^{2}$ Department of Psychology, Hunter College and the Graduate Center of the City University of New York, 695 Park Avenue, New York, NY 10065, USA. ${ }^{3}$ School of Earth and Environmental Sciences, University of Adelaide, Adelaide, SA 5005, Australia.
}

Received: 2 September 2014 Accepted: 25 September 2014

Published online: 04 October 2014

\section{References}

1. Samas $P$, Hauber ME, Cassey $P$, Grim T: Host responses to interspecific brood parasitism: a by-product of adaptations to conspecific parasitism? Front Zool 2014, 11:34.

2. Pirie M: How to Win Every Argument. New York: Continuum International Publishing Group; 2006.

3. Hauber ME: Hatching asynchrony, nestling competition, and the cost of interspecific brood parasitism. Behav Ecol 2003, 14:224-235.

4. Cassey P, Ewen JG, Blackburn TM, Hauber ME, Vorobyev M, Marshall NJ: Eggshell colour does not predict measures of maternal investment in eggs of Turdus thrushes. Naturwissenschaften 2008, 95:713-721.

5. Grim T, Samaš P, Moskát C, Kleven O, Honza M, Moksnes A, Røskaft E, Stokke BG: Constraints on host choice: why do parasitic birds rarely exploit some common potential hosts? J Anim Ecol 2011, 80:508-518.
6. Grim T, Honza M: Differences in behaviour of closely related thrushes (Turdus philomelos and T. merula) to experimental parasitism by the common cuckoo Cuculus canorus. Biologia 2001, 56:549-556.

7. Grim T: Cuckoo growth performance in parasitized and unused hosts: not only host size matters. Behav Ecol Sociobiol 2006, 60:716-723.

8. Yang C, Stokke BG, Antonov A, Cai Y, Shi S, Moksnes A, Røskaft E, Møller AP, Liang W, Grim T: Host selection in parasitic birds: are open-cup nesting insectivorous passerines always suitable cuckoo hosts? J Avian Biol 2013, 44:216-220

9. Underwood TJ, Sealy SG, McLaren CM: Experiments on egg discrimination in two North American corvids: further evidence for retention of egg ejection. Can J Zool 2004, 82:1399-1407.

10. Samaš $P$, Grim T, Hauber ME, Cassey P, Weidinger K, Evans KL: Ecological predictors of reduced avian reproductive investment in the southern hemisphere. Ecography 2013, 36:809-818.

11. Soler M, Ruiz-Castellano C, Fernández-Pinos MC, Rösler A, Ontanilla J, Pérez-Contreras T: House sparrows selectively eject parasitic conspecific eggs and incur very low rejection costs. Behav Ecol Sociobio/ 2011, 65:1997-2005.

doi:10.1186/s12983-014-0072-y

Cite this article as: Samas et al:: The evolutionary causes of egg rejection in European thrushes (Turdus spp.): a reply to M. Soler. Frontiers in Zoology 2014 11:72.

\section{Submit your next manuscript to BioMed Central and take full advantage of:}

- Convenient online submission

- Thorough peer review

- No space constraints or color figure charges

- Immediate publication on acceptance

- Inclusion in PubMed, CAS, Scopus and Google Scholar

- Research which is freely available for redistribution 